\title{
A CASE OF FILARIASIS OCULI
}

BY

K. Koman NayaR, D.O.M.S.

ACTING SUPERINTENDENT, GOVERNMENT OPHTHALMIC HOSPITAL, MADRAS

AND

\section{A. Kandaswami Pillai}

IN CHARGE, EYE DEPARTMENT, GOVERNMENT HEADQUARTER HOSPITAL, CALICUT

Kunhi Ahmed, police constable, aged 34 years, reported himself at the Eye Department of the Government Headquarter Hospital at Calicut, Malabar district on June 10, 1931, with the complaint that his left eye vision was blurred and that he had noticed a worm-like object floating about in front of his left eye for the past five days. He did not complain of any symptoms other than a feeling of heaviness on the left side of his head. His medical history sheet showed only three previous admissions into the hospital for malaria and three for bronchitis. His general health was good.

He was examined by Dr. A. Kandaswami Pillai with the following result :-

R.E.V.:=6/6 ; L.E.V. $=6 / 18$, not improved with glasses.

Both pupils active to light and accommodation; tension normal in each eye. The pupils were subsequently dilated with homatropine and adrenalin for fundus examination.

Right eye : Fundus normal ; media clear.

Left eye : In the vitreous, just in front of the macula, was seen a thread-like, wriggling worm, coiling itself and moving briskly, especially when light was thrown directly on it. There was an oval clot of blood, about three-fourths of the size of the optic disc, near the macula, to which one end of the worm was attached; the other end of the worm kept on moving in different directions in the posterior part of the vitreous. The worm appeared to be, roughly about $3 \mathrm{~mm}$. long at that time. At times a sheath could be made out, as also what appeared to be a few silvery white bands across the worm. Whether these bands were due to reflection of light from the convex surfaces of the loops formed by the moving worm, it is difficult to say.

Blood showed a haemoglobin percentage of 90 , and the result of a differential count was :-

$$
\begin{aligned}
& \text { Polymorphonuclear Per cent } \\
& \begin{array}{lllll}
\text { Lymphocytes } & \ldots & \ldots & \ldots & 56 \\
\end{array}
\end{aligned}
$$

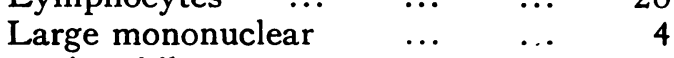

$$
\begin{aligned}
& \text { Eosinophiles } \quad \ldots \quad \ldots \quad \ldots \quad 14 \text { (not at all a high } \\
& \text { percentage among } \\
& \text { the general popula- } \\
& \text { tion of that district) }
\end{aligned}
$$


Night blood-negative for microfilariae.

Physical examination : No enlargement of glands anywhere in the body; no other signs of infection with filaria.

At the request of one of the authors (K. K. N.) who was shown the case while at Calicut on a holiday and verified the ophthalmoscopic findings, the patient was sent over to the Government Ophthalmic Hospital, Madras for further observation and investigation.

On June 20 and subsequently, before sending the patient to Madras, Dr. A. Kandaswami Pillai noted that the movements of the worm were getting slower, the patch of retinal haemorrhage was getting smaller in size and the worm was gradually getting longer.

The patient reached Madras on the morning of June 24, 1931, after a railway journey of over 400 miles. On arrival he gave the history that sometime during the previous night, when awake, he suddenly saw flashes of red and green sparks in front of his eye and that afterwards, he lost sight of the moving object in front of the eye.

On external examination, both eyes were found normal in appearance.

R.E.V:=6/6, partly; L.E.V.=6/6, partly, not improved with glasses.

Pupils active, right fundus normal and media clear.

In the left fundus, the remains of the old haemorrhage were seen near the macula. There were also numerous shiny white spots in the vitreous just in front of the macular region, but no sign of the worm could be made out in the eye.

Examination of the peripheral blood of the patient taken at night on different occasions showed microfilaria (bancrofti).

The patient was under observation daily and the haemorrhage was found to get smaller in size and the vitreous in front of the macular region clearer.

On June 29, the worm was found lying in the bottom of the anterior chamber and moving about briskly when light was thrown on it. It was greyish white in colour and was approximately $2.5 \mathrm{~cm}$. in length and less than $0.5 \mathrm{~mm}$. in width. The appearance was that of an adult filaria. Details could not be made out by biomicroscopy as the worm became very active when light was thrown on it.

The patient was kept under observation for a few days and the worm was daily seen lying at the bottom of the anterior chamber. The mobility of the worm remained much the same from day to day. The patient observed the presence of the floating object in front of his eye now and then.

On July 2, it was decided to remove the worm from the anterior 
chamber; after the usual preliminaries, a small keratome incision was made at the limbus below; the aqueous rushed out through the wound, evidently carrying the worm with it, but unfortunately the worm was lost in spite of all precautions. The anterior chamber was refilled with normal saline but no trace of the worm could be made out. On July 10 , the patient was discharged from the hospital with the eye quiet, with a vision of $6 / 9$, improving to $6 / 5$ save one letter with $+0.75 \mathrm{D}$. sph. (tested while the pupil was still dilated). The anterior part of the eye, as examined with the corneal microscope, was found to be normal.

The patient came from a district where filariasis is fairly common; his peripheral blood contained microfilaria bancrofti. The size of the worm and its appearance leave little doubt that it was an adult filaria. Although the measurements of the worm as judged from its appearance in the anterior chamber are approximate, they are within the limits of the measurements given by Cruickshank and Wright in their investigation "Filariasis in Cochin" (Malabar coast) in 1914. (Ref : The Indian Journal of Medical Research, Vol. I, No. 4, 1914.)

The case is interesting on account of its rarity-only a few cases having been recorded so far in the human eye, of which a list is given by Elliot in his book "Tropical Ophthalmology." Unfortunately, in this case, just as in those quoted, the nature of the parasite was not determined with certainty. Probably no case has been recorded till now in which a filaria was seen emerging from the retina or subretinal space gradually pushing itself forward into the vitreous and then disappearing altogether for a few days before making its appearance in the anterior chamber, where it remained free and alive for some days without causing any reaction in the eye or any inconvenience to the patient.

I discussed the case with Lt.-Col. R. E. Wright, I.M.S., on his return from leave and submitted my records and a drawing. He added the following note, which I quote in full :-

"As far as I know there has not been any case of an intra-ocular filarial worm reported which has a greater claim to be regarded as bancrofti. The patient came from an area where bancrofti and only bancrofti is endemic, there were microfilariae bancrofti in the blood. The thickness, length and conformity as far as I can gather from your numerous observations, place it within the limits of the series of adult filariae described and figured by Cruickshank and me in 1914, the length of smallest worm being $20 \mathrm{~mm}$. These were taken from lymphatic glands of patients in an adjoining district ; we did not see any intra-ocular filariasis during our survey. R. E. Wright." 